\title{
The Facial Shapes in Planning the Treatment with Injectable Fillers
}

\author{
André Braz ${ }^{1}$ Camila Cazerta de Paula Eduardo² \\ ${ }^{1}$ Dermatologia Laser Cosmiatria Clinic, Rio de Janeiro, RJ, Brazil \\ ${ }^{2}$ Aesthetike Plastic Surgery and Dermatology, Sao Paulo, SP, Brazil
}

\begin{abstract}
Address for correspondence: André Braz, Dermatologia Laser Cosmiatria Clinic, Visconde de Pirajá, 330, cj 1001 22410-003, Rio de Janeiro, Brazil (e-mail: avbraz@globo.com)
\end{abstract}

\begin{abstract}
Keywords

- botulinum toxin

- dermal filler

- face

- facial rejuvenation

- nonsurgical

Introduction The facial beauty is not easy to define, yet it is paramount to assess the needs of each patient to propose an appropriate treatment plan that will provide beautification or rejuvenation in a natural-looking fashion.

One of the beauty aspects easily recognized is the face shape, which can give a perception of age, gender, and attractiveness, and reflects the facial anatomical structure. Because addressing the structure of the face is the basis for the aesthetic approach with dermal fillers, we find the identification of the patient's face shape to be a very good starting point in the facial assessment.

Objective To discuss important aspects of facial beauty, the characteristics of the different facial shapes (oval, heart, round, and angular), and a method of planning the aesthetic treatment with injectable fillers based on the strengths and weaknesses of each morphology of the face, that is called the $A B$ face technique.

Methods In this study, we describe seven clinical cases: two cases each of oval, heart, and round, and one case of angular shape.

Results The evaluation of the face shape can help us define the priorities of the aesthetic approach, determining the areas that need to be restored in the aging face, as well as which areas could be enhanced in the younger patient.

Conclusion This approach can be helpful in proposing the aesthetic treatment plan with injectable fillers to provide beautification, rejuvenation, and enhancement of the facial structure, which may benefit facial contours through aging.
\end{abstract}

\section{Introduction}

A beautiful face can be universally recognized, ${ }^{1}$ nevertheless it can be difficult to define. It is a result of the bone structure, the position and volume of the subcutaneous tissue, the skin quality, and the personality of each person, expressed in the facial movements. ${ }^{2-4}$

Balance, symmetry, averageness, and sexual dimorphism are facial attributes attractive to the human being. ${ }^{2.5}$ Balance is described as the harmonious proportions of the facial thirds, the vertical fifths, and other remarkable features, as the eyes, nose, and lips. Symmetry between the sides of the face in the vertical axis is an important aspect, although not determinant, as small asymmetries are found to be attractive and to define the individuality of a face.

Averageness is a concept in which we tend to find more beautiful an average of attractive faces than the individual characteristics of a single face. ${ }^{1,6}$

Finally, the sexual dimorphism, that refers to the differences of structure and features between the genders. A woman's face that possesses feminine attributes, a gentle curve, and soft lines is considered more attractive, and the same happens with a man's face exhibiting masculine features such as sharp angles and lines. ${ }^{2}$
DOI https://doi.org/

10.1055/s-0040-1715554

ISSN 0970-0358.
License terms

() (1) $\ominus \circledast$ 
The facial beauty cannot be defined in a mathematical formula or by a single concept, yet it is paramount to assess the needs of each patient ${ }^{5,7}$ through the identification of facial strengths and weaknesses to be able to propose an appropriate treatment plan that will provide beautification or rejuvenation in a subtle and natural-looking fashion.

One of the beauty aspects easily recognized is the face shape, which gives a perception of age, gender, and attractiveness, ${ }^{7}$ and reflects the facial anatomical structure comprised of bone, adipose, and skin tissues. ${ }^{\text {? }}$

Because addressing the structure of the face is the basis for the aesthetic approach with dermal fillers, we find the identification of the patient's face shape to be a very good starting point in the facial assessment.

The evaluation of the face shape can help us define the priorities of the aesthetic approach and determine the areas that need to be restored and volumized in the aging face, as well as what could be done to enhance the facial beauty in the younger patient and, moreover, how to optimize the face structure and contribute to the aging well.

The methodology that will be discussed in this study is based on the authors' personal experience. It is called $A B$ face technique, which stands for "anatomy of beauty" and comrpises two steps. The first is the AB structure, which is based on the facial shapes, improving the contours and proportions of the face to enhance the patient's beauty. The second step is called AB refinement, with the aesthetic goal of blending and smoothing the areas treated and correcting the remaining sulcus and grooves. This study will prioritize the former, although both steps can be performed at the same moment. The objective of this study is to give an insight in the assessment of facial beauty and aging, which could be helpful in designing an aesthetic treatment plan with injectable fillers, aiming at optimal outcomes for the patients.

We understand that the nonsurgical aesthetic approach comprises a combination of methods and techniques, including botulinum toxin injection, laser and other technologies, chemical peels, which are discussed elsewhere and are not in the scope of this study.

\section{The Facial Shapes}

The facial shape is the first thing captured by the sight from a greatest distance when we see another person. It can reflect aspects of beauty, sexual dimorphism, and age.

The smooth egg-shaped contours, named the oval female face, suggests a youthful feminine face and is globally understood as beautiful, ${ }^{2,7}$ whereas a masculine face is more angular and sharper. ${ }^{8}$

Although the oval shape is recognized as attractive among different cultures and ethnicities, other female facial shapes are also beautiful; once uniqueness is attractive, the concept of beauty is subjective and involves a group of combined features harmonious together. In fact, as an example, the contemporary female facial beauty values more angled and defined lines, as we can see in fashion shows, social media, and films.
Aging is associated with a volume shift from the upper to the lower face, transforming the oval shape into a rectangular one. ${ }^{7}$ There is decrease of volume inperiorbital, malar, and submalar areas, in addition to increase of volume in jowl, determining the loss of definition in the mandibular contour and face-neck transition. ${ }^{9}$

The classifications of facial morphology have mainly arisen from the studies in anthropology and forensic medicine. ${ }^{10,11}$ Different models of facial shapes have been used over the time, varying from 7 to 10 categories. ${ }^{11}$

In our personal opinion, using a classification with a smaller number of specific facial shapes is easier to understand and more practical in the definition of the aesthetic treatment plan. For that reason, we have been using four face shape models: oval, heart, round, and angular ( - Fig. 1).

It is important to mention that we characterize the shapes taking into account the middle and lower thirds of the face, instead of the whole face. The first reason we prefer this approach is that the hair implantation line and the hairstyle may confuse the evaluation and, consequently, the classification of the proper face shape. Second, although the upper third is key to the rejuvenated and attractive appearance, the goals of the treatment with fillers do not considerably change among different morphologies of the face. The end points are a rounder forehead in women and a sharp oblique frontal in men, whereas the temples should be slightly concave or flat in both genders.

Of note, some patients may have facial asymmetries that can lead to a different shape at each side of the face, which is important to be identified in the facial assessment.

\section{Methodology}

We will describe our method of designing the treatment plan, with the aim to improve the structure of the face, using the four face shapes (oval, heart, round, and angular), which is the first step of the $A B$ face technique, which is called $A B$ face structure. In this study, we will describe seven clinical cases: two cases each of oval, heart, and round, and one case of angular shape.

The facial areas that can be treated are shown in $\mathbf{- F i g} \mathbf{2}$.

In the younger patient, the aesthetic goals may be beautification through the enhancement of the facial features or correction of constitutional deficiencies along with early intervention to rejuvenation.

For rejuvenation treatments, the aesthetic goals may be restoration of facial volume or lifting, as well as beautification.

Whatever is the case, the general objective of this approach is to improve the structure of the face. Therefore, the appropriate injection depth is middle or deep subcutaneous or supraperiosteal, depending on the anatomical area. It is important to mention that the knowledge of regional anatomy is crucial to perform safe and effective treatments. We recommend the use of cannulas, which can achieve larger areas with smaller risk of vascular adverse events than injection with needles. In our experience, the more suitable fillers are the high-elasticity or high-density hyaluronic acid gels or composite gel matrix of hyaluronic acid (70\%) and calcium 

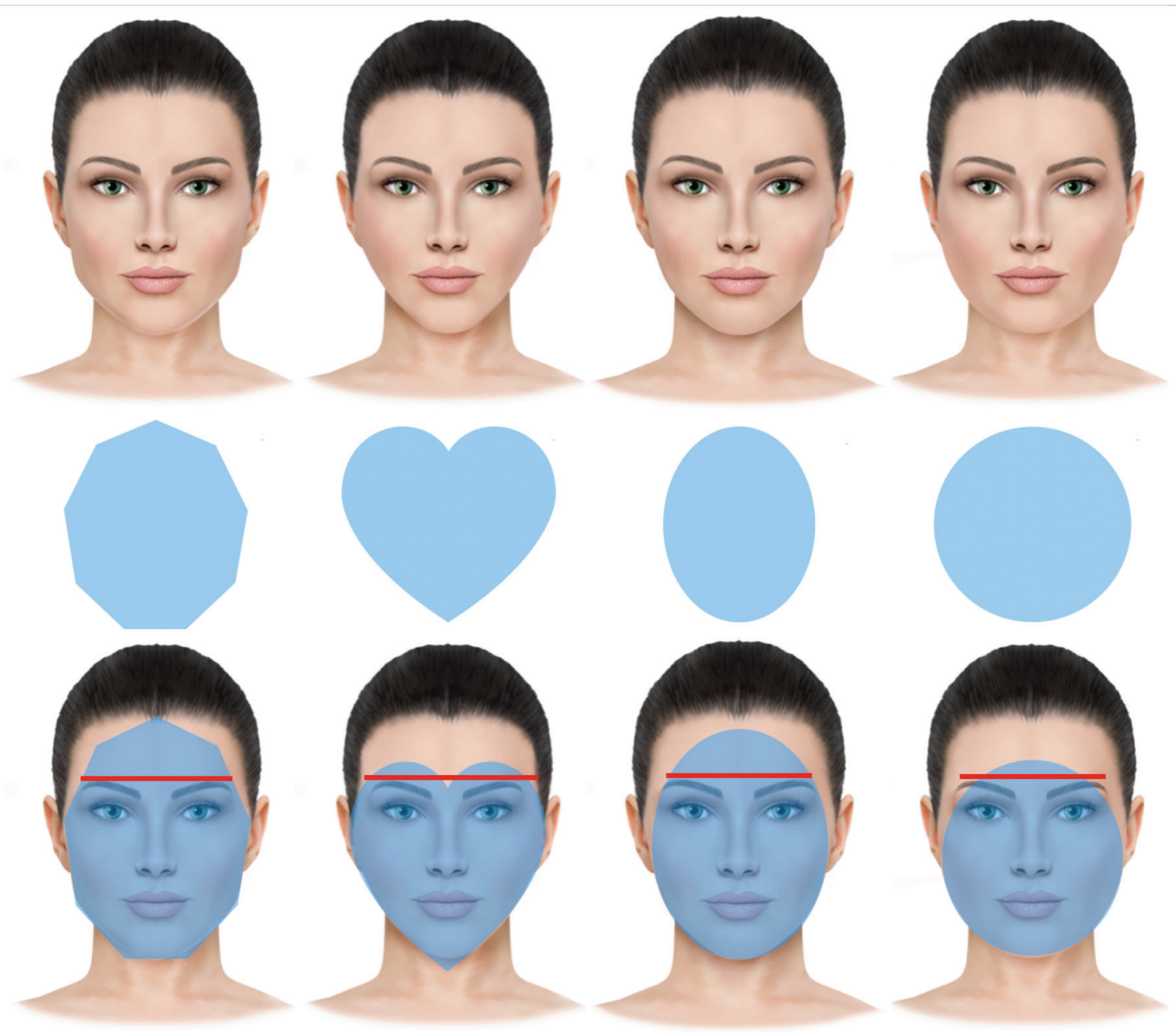

Fig. 1 The face shapes: angular, heart, oval, and round. It is important to mention that the angular shape does not refer to a specific geometrical figure, as the angles may vary.

hydroxyapatite (30\%), such as Harmonyca (U.SK Underskin), provided in syringes of $1.25 \mathrm{~mL}$. The hyaluronic acid fillers used in the clinical cases presented is this study are the Hydryalix range (U.SK, Underskin): ultradeep, high elasticity gel; deep, a medium elasticity gel; gentle, a soft filler; and lips.

It is fundamental to consider the patient's preference as well as to discuss the patient's expectations of the treatment. We recommend signing a consent form. For the proper indication of the injectable procedure, clinical assessment is essential ${ }^{12}$ in addition to the aesthetic evaluation in upright position, at rest and in animation, taking photos in frontal, oblique, and profile positions.

The facial shape does not necessarily need to be changed in an aesthetic approach with fillers. However, when doing so, the structure of the face may be improved, favoring the maintenance of better facial volume and contours over the time.

Each face shape has a different structure and thus ages differently. A didactic illustration of the aging process of different face shapes is presented in $\boldsymbol{\bullet}$ Fig. $\mathbf{3}$.
In this context, the treatment with filler may be used to enhance the features of the face shape, improving the appearance and contributing to the aging well, as well as to structure into another face shape. The oval face shape can be structured into a more angular one, with caution to keep the femininity, for example.

Other possibilities may be as follows:

- The heart-shaped face may be treated to become more oval or angular.

- The round face can be treated to become closer to an oval face.

- Finally, the angular face can be smoothed into an ovalshaped face.

We will describe in more details the strengths and weaknesses of each facial shape and our treatment suggestions for patients with different face shapes using injectable fillers. Only for a didactic purpose, we have classified the structure of the face (bone and soft tissue) into (1) fragile, (2) moderate, and (3) good. 


\section{AB face}

\section{Structure}

\section{- ML- Malar lateral \\ - ZM- Zigoma medial \\ - ZL- Zigoma lateral \\ - MT- Mental \\ - SM-Submental \\ - PJ- Prejowl \\ JL- Jawline \\ JR- Jaw ramus.}

- MP- Malar prominence
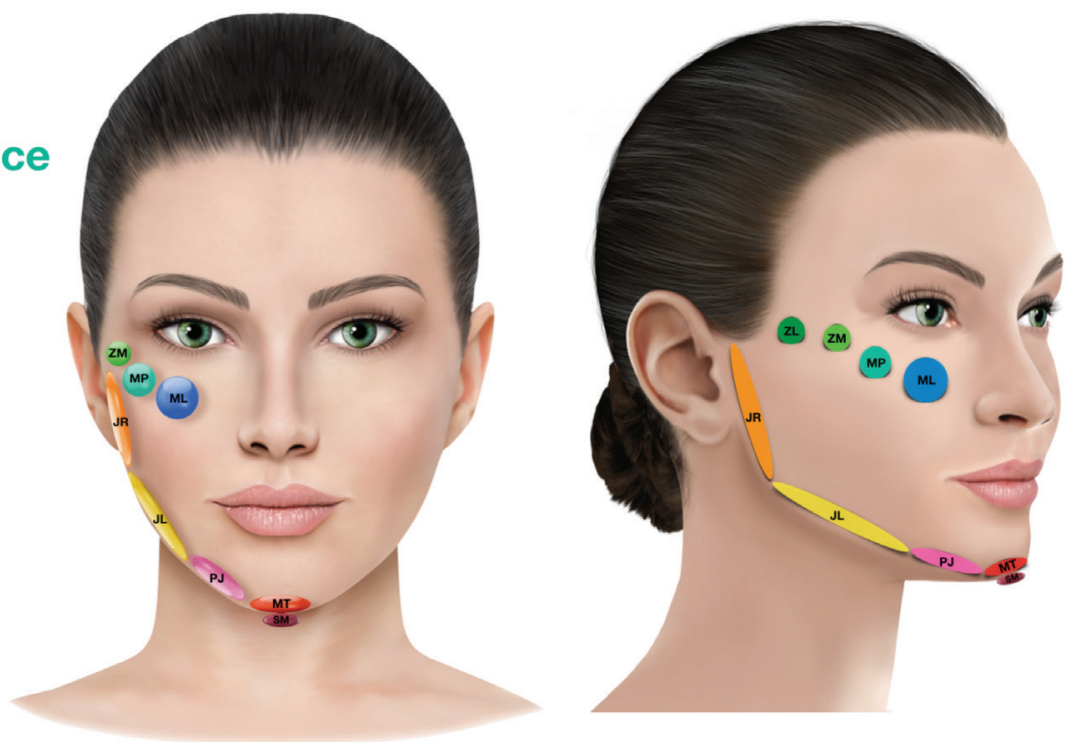

Fig. 2 AB face structure: the anatomical areas of treatment. In the midface, the appropriate injection depth is subcutaneous deep and superficial. The possible planes of injection in the mental and prejowl areas are subcutaneous deep and superficial, whereas the jawline and jaw ramus should be treated as subcutaneous. The recommendation is to use a 22-gauge cannula.

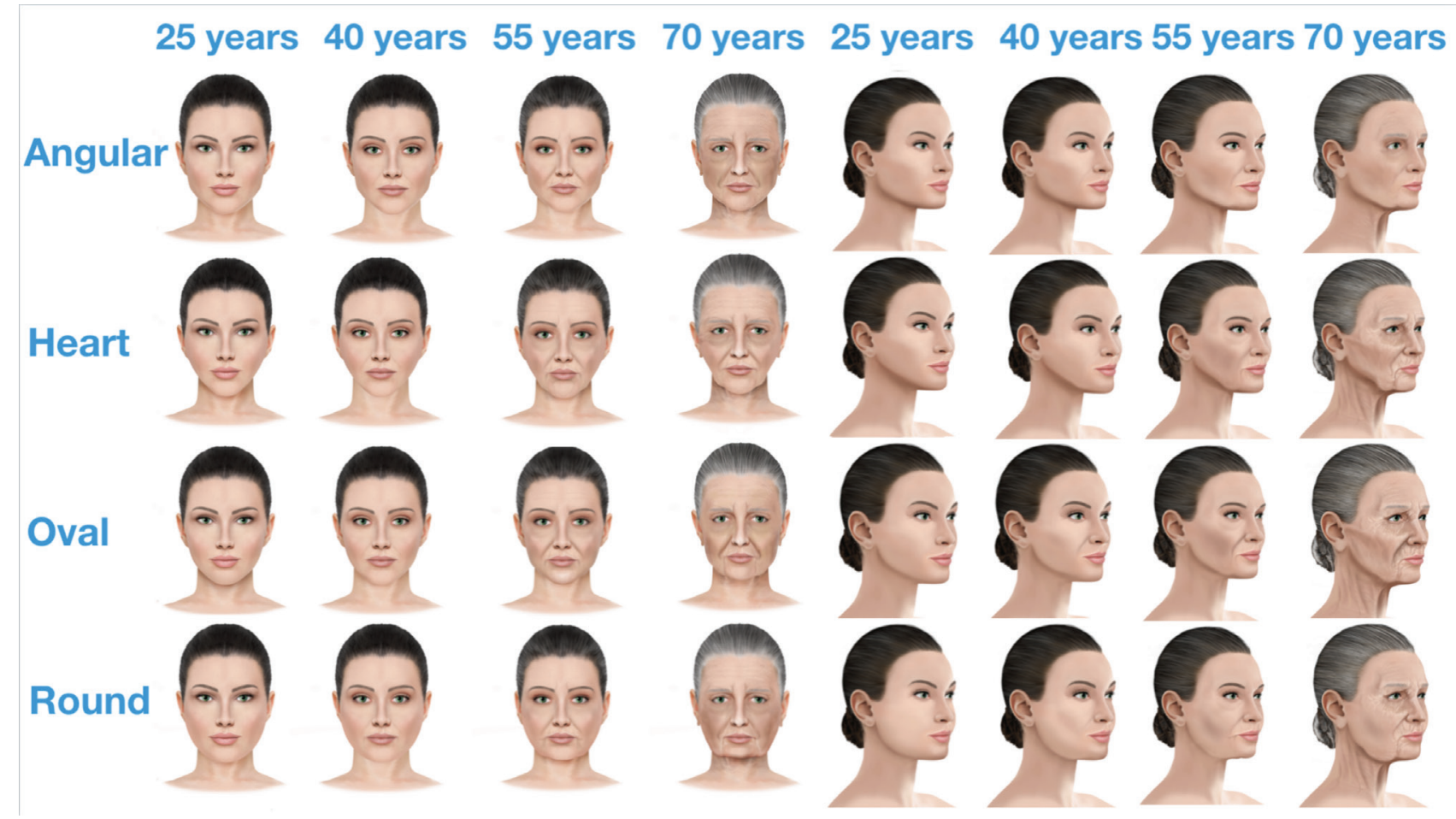

Fig. 3 The aging process in the different face shapes. This image illustrates that each face shape ages differently. This is the reason that the treatment plan varies among the distinct shapes. 


\section{Treatment Strategy for the Oval Face Shape}

This shape has good proportions and symmetry. It has a wider midface in comparison to the lower face, with a subtle and soft narrowing toward the chin. There is a moderate facial support in the middle and lower thirds of the face.

- Strength: proportional middle and lower faces

- Weakness:

- 2- moderate structure of the midface

- 2- moderate structure of the lower third

Thus, in the aging process, the weakness in the middle and mainly the lower face leads to jowling and loss of facial contour. For beautification or rejuvenation, specific concerns should be addressed, replacing volume in the malar and zygomatic areas. Moreover, the structure of the face may be enhanced using fillers in the entire mandibular line, including the mandibular angle ( - Fig. 4).

- Injection order: Middle third and then the lower third from medial to lateral (-Figs. 4-6).

\section{Treatment Strategy for the Heart Face Shape}

In this facial shape, the bizygomatic distance is larger than the bigonial distance, with a wider middle third and a deficiency in the lower third, with a remarkable narrowing in the chin region. The light projection is on the midface, along with shadowing in the jawline and mandible angle.

In the aging process, there is a tendency to lose contour in the lower third, presenting considerable laxity in this area. Diversely, the middle third of the face shows less obvious changes, with loss of volume mainly in its anterior and medial portions.

- Strength: 3- good structure of the middle third

- Weakness: 1- fragile structure of the lower third

The main points for the treatment strategy with injectable fillers (-Fig. 7):

- In the middle third of the face, the volume should be injected mainly in the middle or anterior portion, with less volume of product placed laterally in the zygoma and malar prominence.

- In the lower third of the face: promote projection of the mentonian area, secondarily a slight elongation of this region.

- The priority treatment areas, in the whole face, are the prejowl, the jawline, and the mandible angle, where the larger volume of product should be placed.

- Injection order: middle third and then the lower third from medial to lateral

Clinical examples in - Figs. 8 and $\mathbf{9}$.

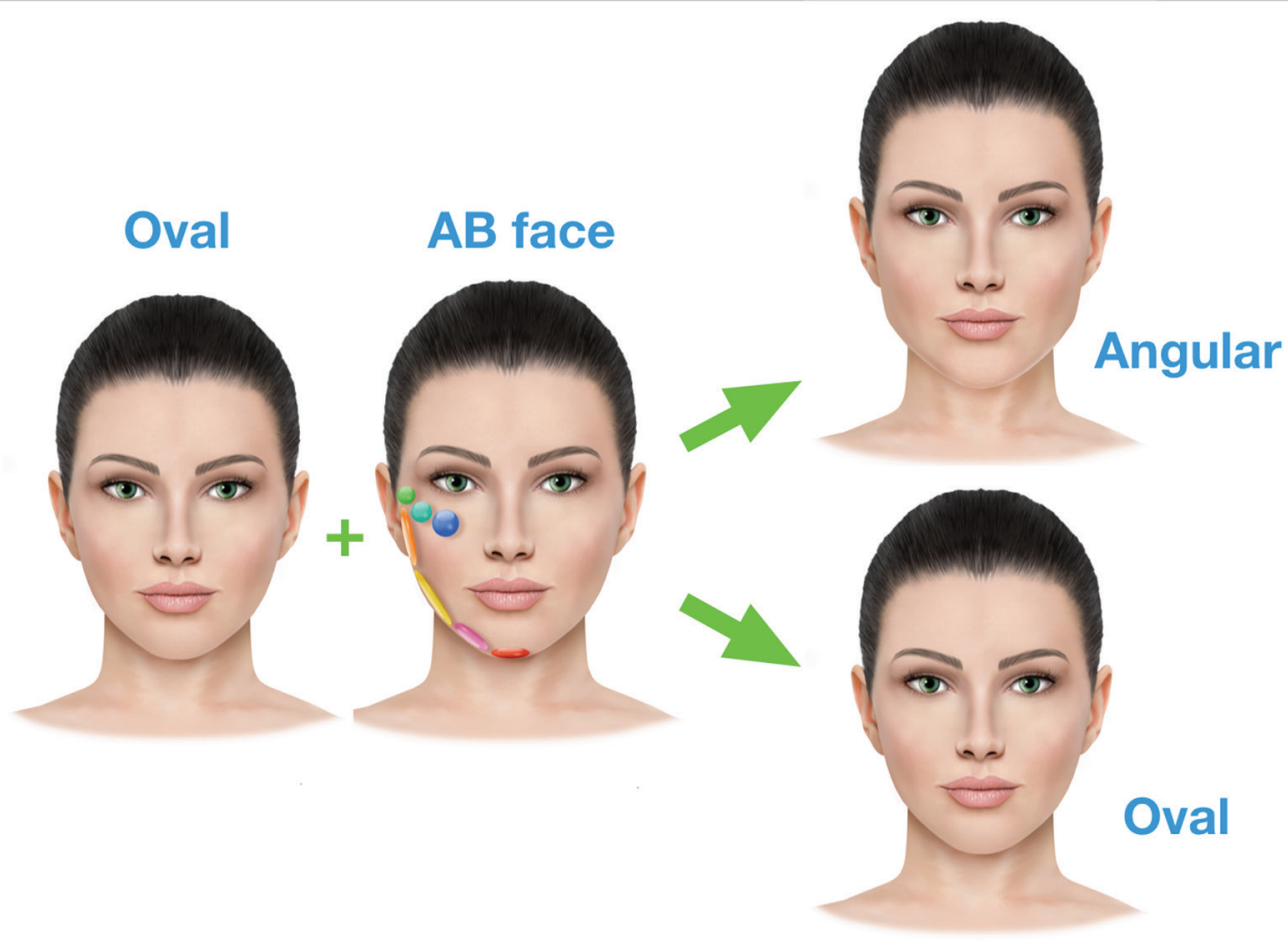

Fig. 4 The treatment plan for the oval face shape: it is possible to structure it into a more angular shape, or the treatment with injectable filler may be used to enhance the oval, aiming to improve the facial contours. In general, the volume of filler is distributed in the following proportion: 45 to $50 \%$ in the middle third and 65 to $50 \%$ in the lower third. 


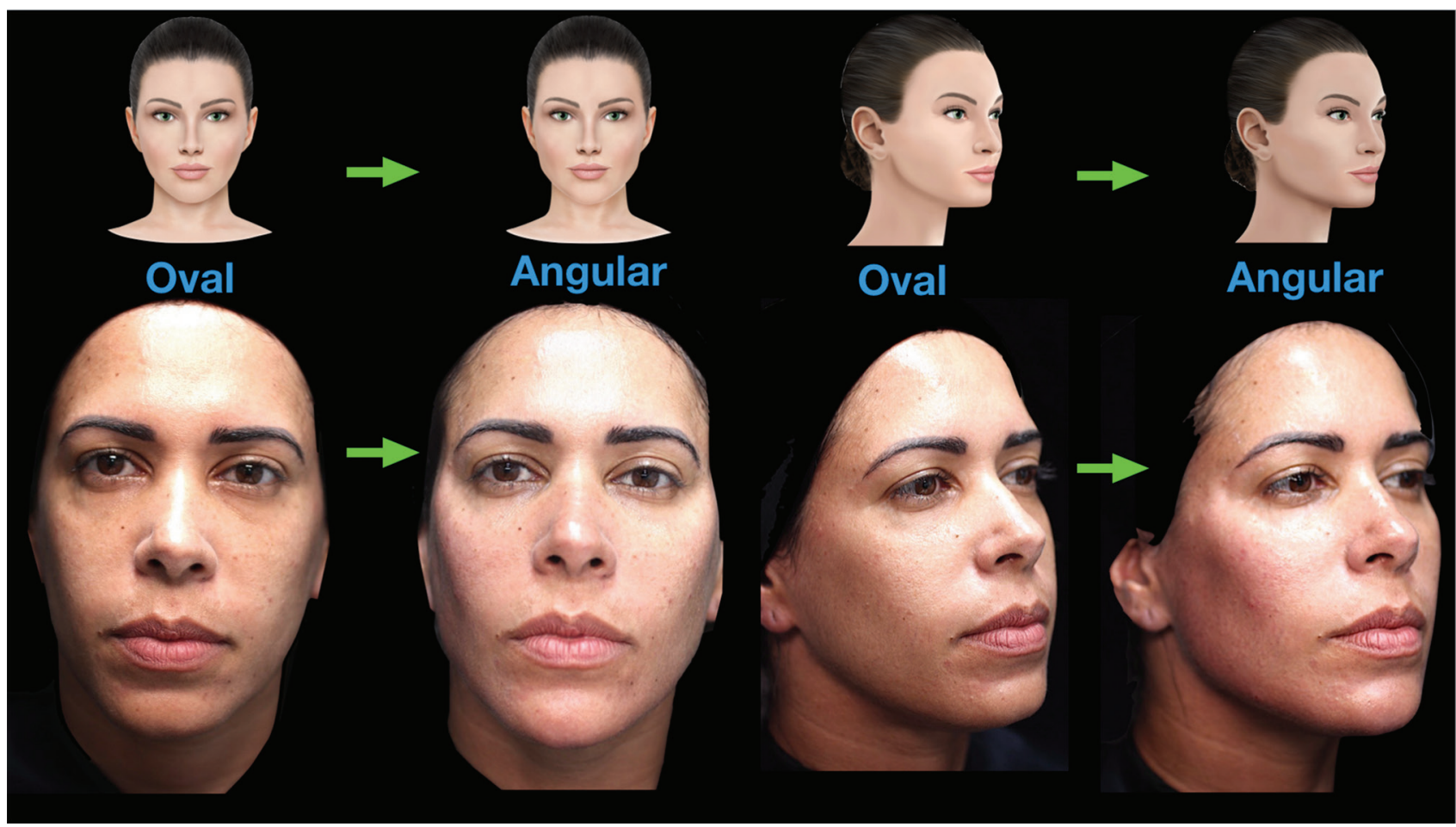

Fig. 5 Clinical case of a patient with an oval face shape treated with the $A B$ face technique to structure the face into a more angular shape. Hydryalix ultradeep hyaluronic acid with high elasticity was used in the following areas: malar lateral $(0.8 \mathrm{~mL})$, malar prominence $(0.8 \mathrm{~mL})$, zygoma medial $(0.8 \mathrm{~mL})$, zygoma lateral $(0.6 \mathrm{~mL})$, mental $(0.8 \mathrm{~mL})$, prejowl $(1.2 \mathrm{~mL})$ (total: $5 \mathrm{~mL}$; four syringes). Harmonyca, two syringes of $1.25 \mathrm{~mL}$ was used in the jawline $(1.25 \mathrm{~mL})$ and ramus $(1.25 \mathrm{~mL})$. The refinement technique was performed with Hydryalix deep, with medium elasticity, $1.25 \mathrm{~mL}$ in the nasolabial and labiomental folds. Total volume used: $8.75 \mathrm{~mL}$.

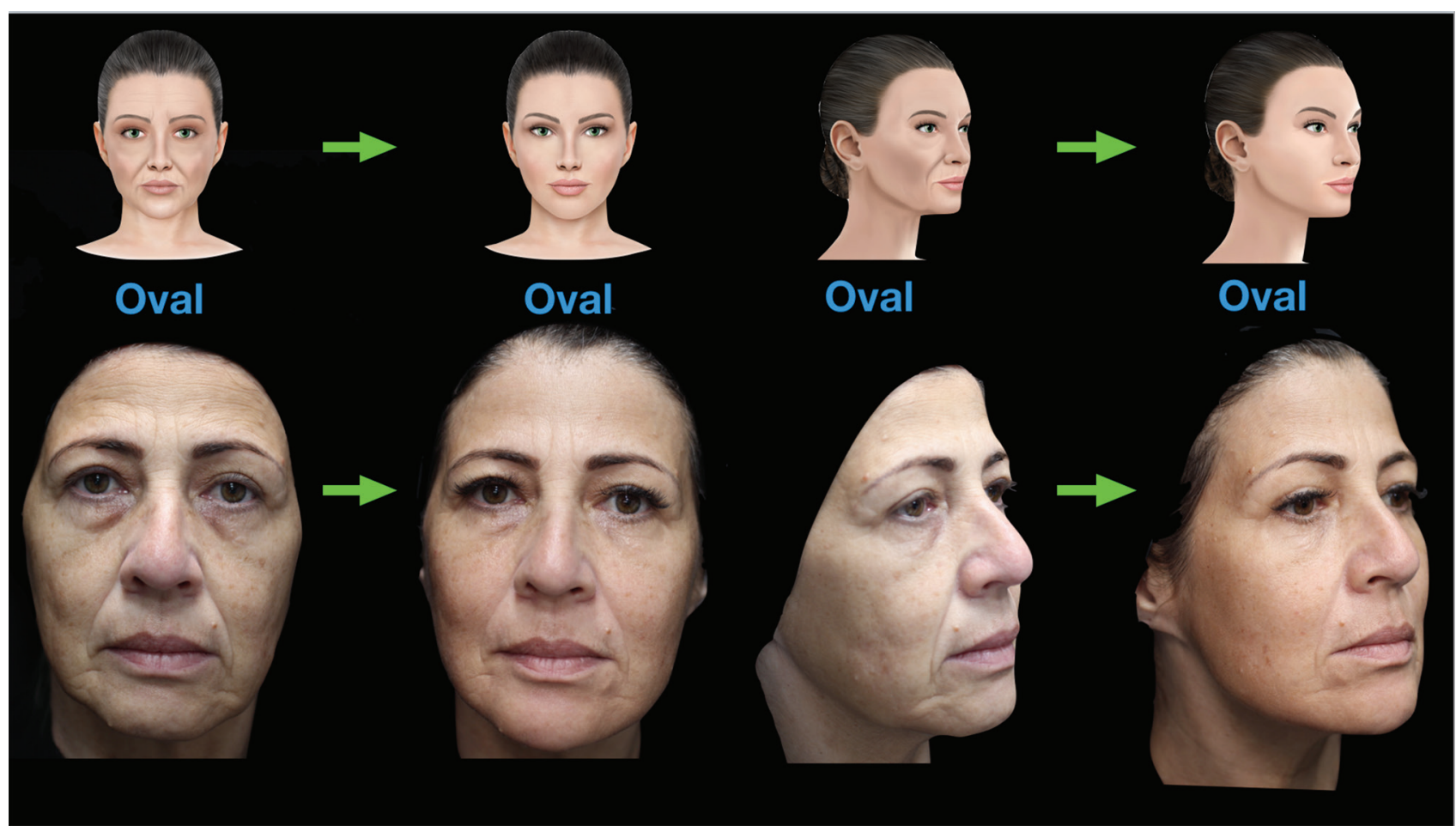

Fig. 6 Clinical case of a patient with an oval face shape treated with Harmonyca using the AB face structure technique to rejuvenate the face. Total volume used was $7.5 \mathrm{~mL}: 2.5 \mathrm{~mL}$ in the midface and $5 \mathrm{~mL}$ in the lower face (malar lateral: $0.6 \mathrm{~mL}$; malar prominence: $0.6 \mathrm{~mL}$; zygoma medial: $0.6 \mathrm{~mL}$; zygoma lateral: $0.6 \mathrm{~mL}$; mental: $1 \mathrm{~mL}$; prejowl: $1.2 \mathrm{~mL}$; jawline: $1.5 \mathrm{~mL}$; ramus: $1.3 \mathrm{~mL}$ ). The AB face refinement was not performed in this case. 


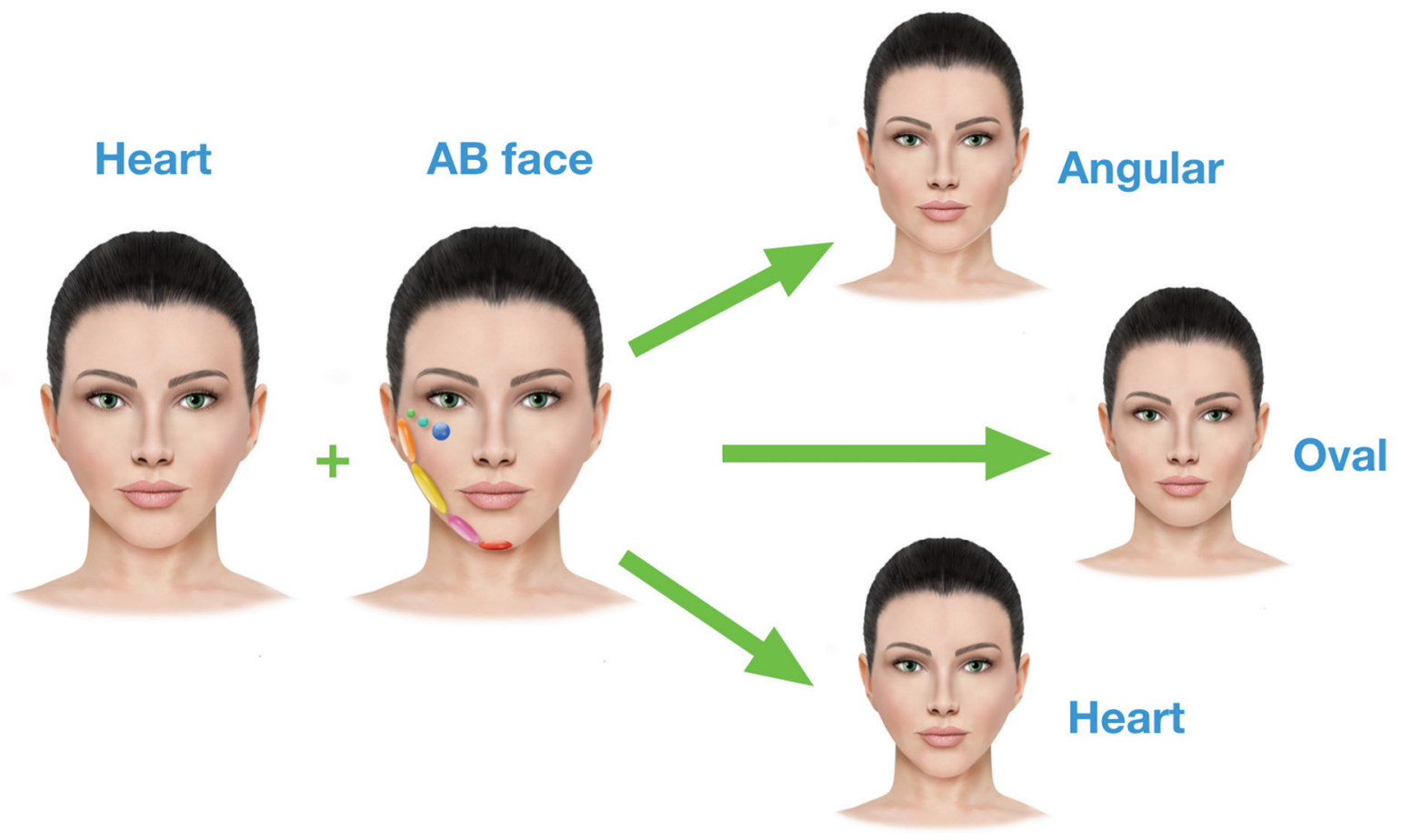

Fig. $7 \mathrm{AB}$ face technique treatment plan for the heart-shaped face. It is possible to restore the volume and enhance beauty without changing the shape or alternatively to structure into a more oval or angular face shape. In general, the volume of filler is distributed in the following proportion: $20 \%$ in the middle third and $80 \%$ in the lower third of the face.

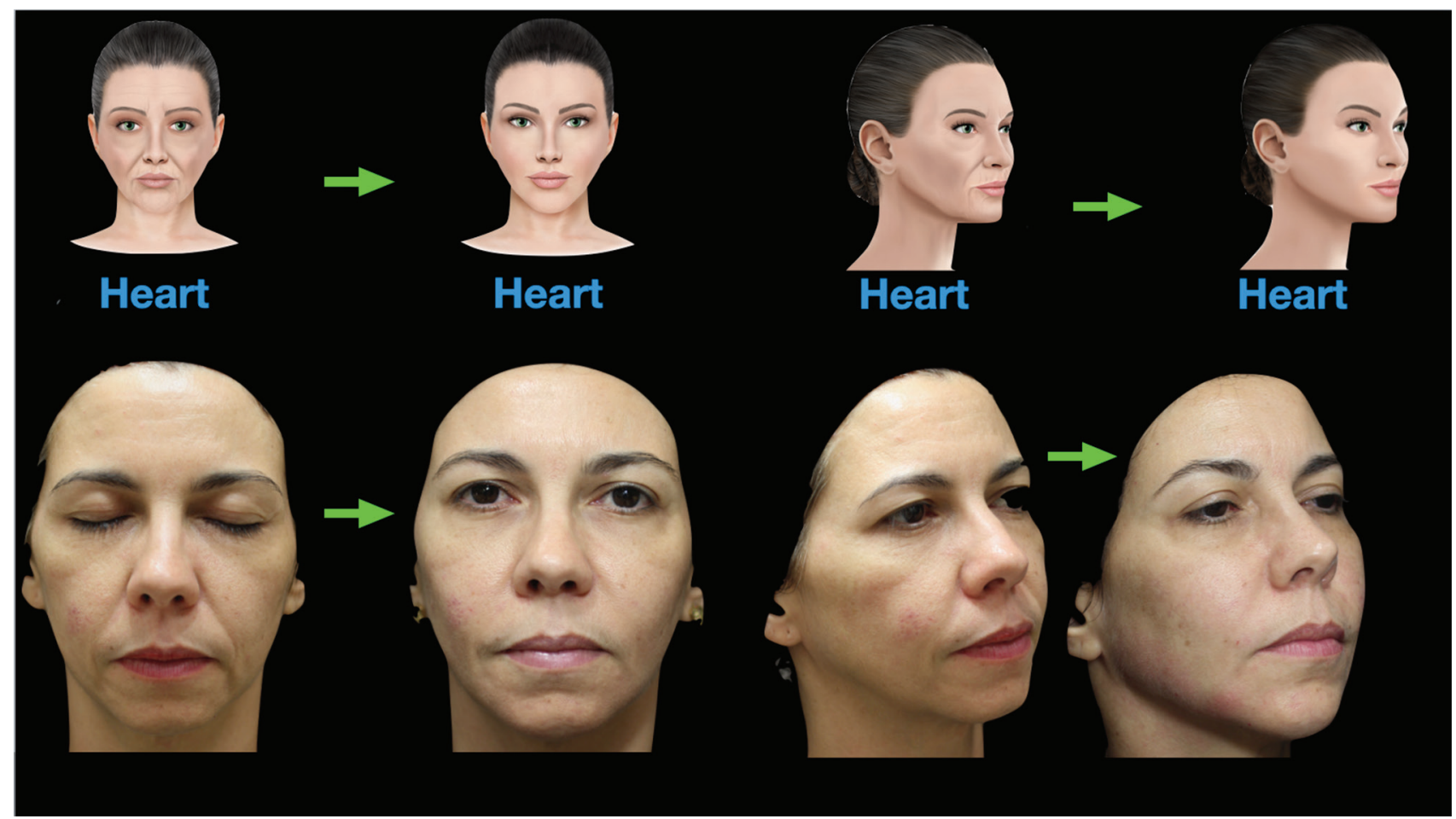

Fig. 8 Clinical example of a patient with a heart-shaped face treated with Harmonyca using the $A B$ face structure technique. $8.75 \mathrm{~mL}$ of the product was used (seven syringes), $1.75 \mathrm{~mL}$ in the midface and $7 \mathrm{~mL}$ in the lower face: malar lateral $(0.6 \mathrm{~mL})$, malar prominence $(0.6 \mathrm{~mL})$, zygoma medial $(0.6 \mathrm{~mL})$, mental $(1 \mathrm{~mL})$, prejowl $(1.4 \mathrm{~mL})$, jawline- $(2.4 \mathrm{~mL})$, and ramus $(2.2 \mathrm{~mL})$. The refinement was performed with Hydryalix deep, $1.25 \mathrm{~mL}$ in the nasolabial and labiomental folds. Total volume used: $10 \mathrm{~mL}$. 


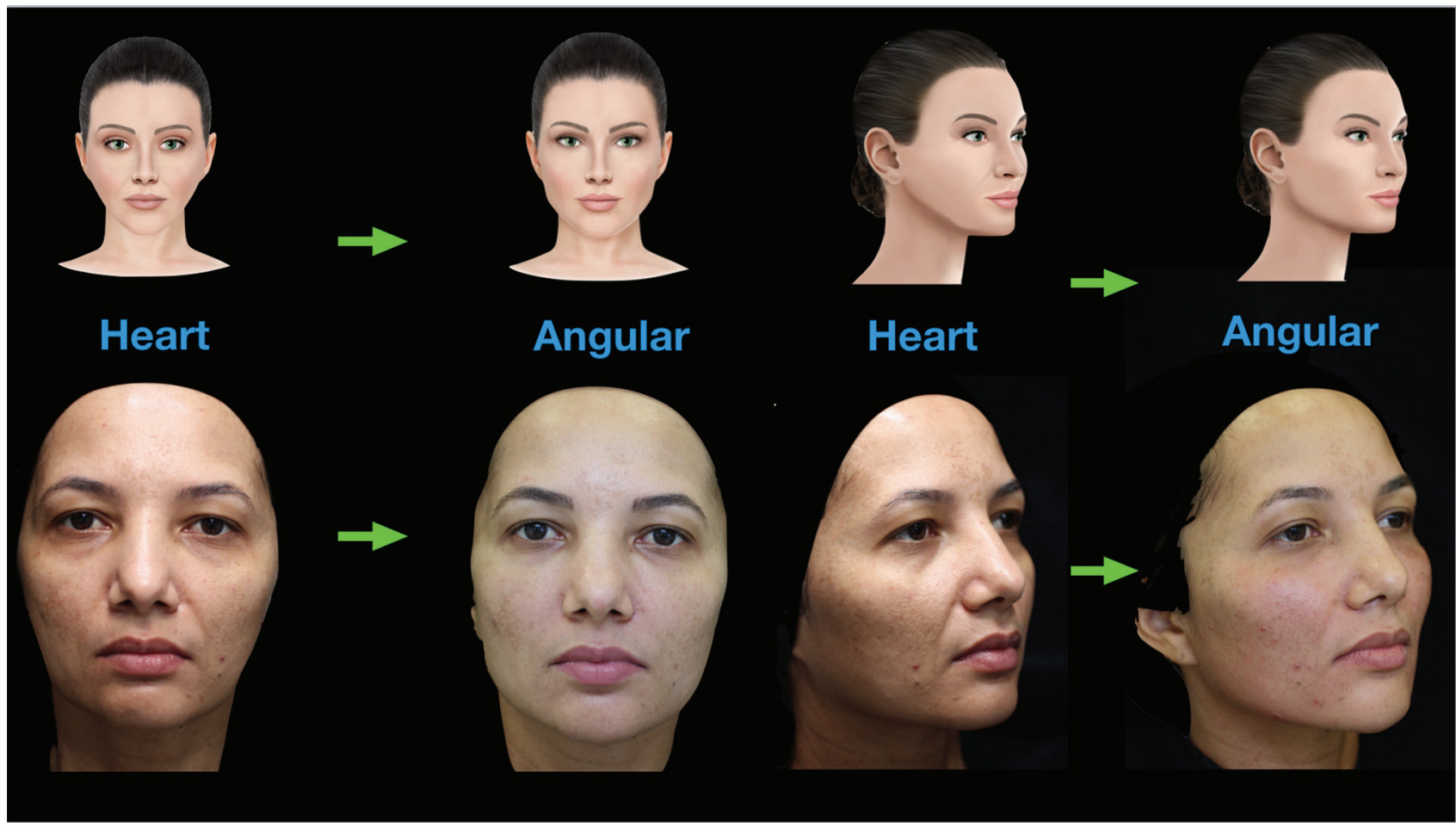

Fig. 9 Clinical example of a patient with a heart-shaped face treated with Harmonyca and Hydryalix ultradeep, deep, and gentle (hyaluronic acid filler of high, medium, and soft elasticity, respectively), using the $A B$ face technique (structure and refinement). Hydryalix ultradeep was used in the middle third $(1.25 \mathrm{~mL})$ : malar lateral $(0.45 \mathrm{~mL})$, malar prominence $(0.4 \mathrm{~mL})$, and zygoma medial $(0.4 \mathrm{~mL})$. Harmonyca was used in the lower third $(3.75 \mathrm{~mL})$ : mental $(0.6 \mathrm{~mL})$, prejowl $(0.6 \mathrm{~mL})$, jawline $(1.25 \mathrm{~mL})$, and ramus $(1.25 \mathrm{~mL})$. Hydryalix deep, $1.25 \mathrm{~mL}$, was used in the nasolabial and labiomental folds. Hydryalix gentle, $0.6 \mathrm{~mL}$, was used in the nasojugal groove. Total volume used: $6.85 \mathrm{~mL}$

After the treament, with a more angular face shape.

\section{Treatment Strategy for the Round Face Shape}

This face has smooth lines, is wider in the middle third, along with a rounded jawline and short mentonian area.

- Strength: 2- moderate structure of the midface.

- Weakness: 1- fragile structure of the lower third.

The treatment goal is to try to elongate the face, giving it structure and support, favoring its lifting, and avoiding augment in the midface volume (-Figs. 10-12).

- In the middle third of the face, the filler should be injected in small-to-moderate volumes, deeply in the subcutaneous or supraperiostal plane, and malar, malar prominence, and zygomatic areas.

- In the lower third of the face, the mentonian area is key for the treatment with fillers, aiming to provide elongation and projection, increasing the facial length.

- The prejowl must be treated, as well as the posterior mandibular line and mandible angle.

- Injection order: middle third and then the lower third from medial to lateral.

Depending on the patient's preference and characteristics, the modification of the face shape can be to an oval, but also to a more angular one. The later can be achieved by shaping straighter angles, using a greater volume of product in comparison to the oval face shape.
We understand that for the optimal aesthetic results, other modalities of therapy, such as botulinum toxin and microfocused ultrasound, are especially important in the approach of this facial shape (-Figs. 10-12).

\section{Treatment Strategy for the Angular Face Shape}

This facial shape has straight lines and a prominent angular jawline. There is a strong structure in the lower third of the face. It must be highlighted that the bizygomatic distance in the feminine angular face is still wider than the bigonial distance, though in the masculine face the bizygomatic distance can be equal or narrower than the bigonial distance.

The angular shape is usually described in the literature in two distinct morphologies ${ }^{11,13}$ : square and rectangular. They are similar in the angles and the difference between them is in the facial length, with the rectangular shape being longer. Therefore, we prefer to classify them both in the angular face morphology, as we evaluate the facial length separately in another step of the facial assessment. The longer faces should be improved in the middle third width, providing more volume in the malar prominence and zygomatic areas.

This morphology of the face usually ages well in its lower third.

- Strength: 3- good structure of the lower third. 


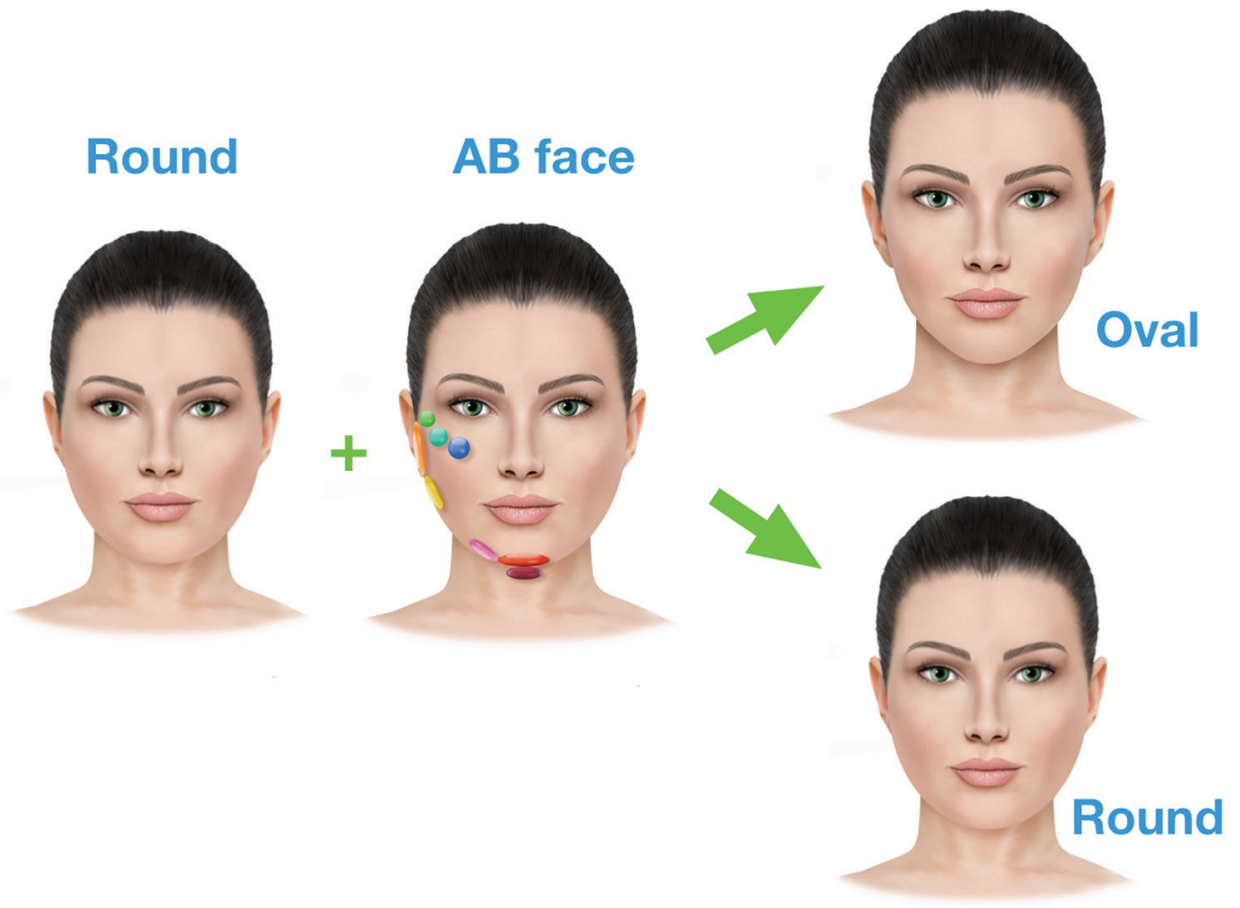

Fig. $10 \mathrm{AB}$ face technique treatment plan for the round-shaped face. The treatment with injectable fillers enhances the structure without changing the shape or may elongate the face into a more oval shape. In general, the volume of filler is distributed in the following proportion: $30 \%$ in the middle third and $70 \%$ in the lower third of the face.

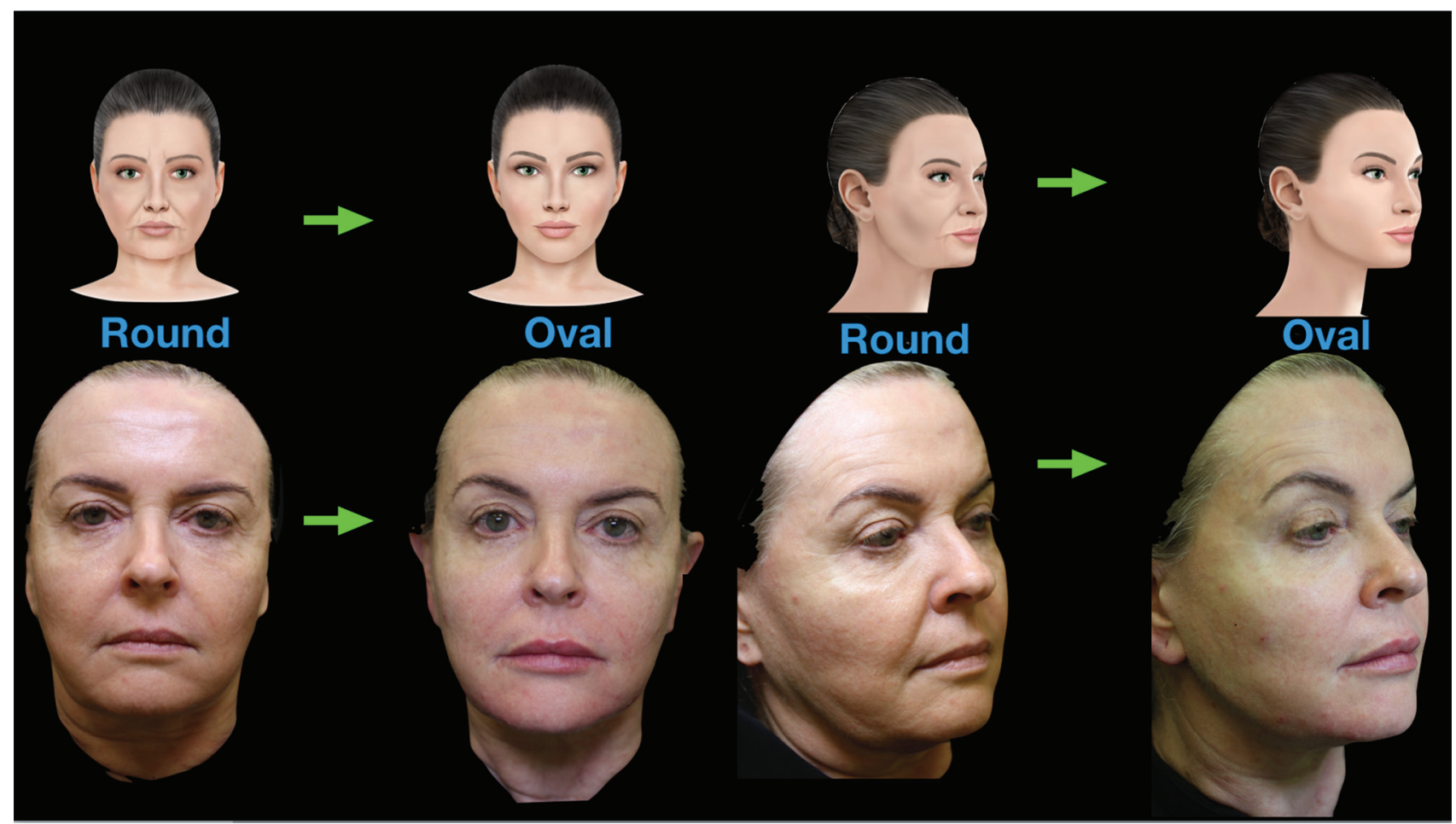

Fig. 11 Clinical example of a patient with a round-shaped face treated with Harmonyca and Hydryalix deep and Hydryalix lips, hyaluronic acid filler, using the $A B$ face technique (structure and refinement). After the treament, with volume restoration, improved contours of the face and a more oval face shape.

Five syringes of Harmonyca, $6.25 \mathrm{~mL}$, were used In the midface $(1.85 \mathrm{~mL})$ : malar lateral $(0.45 \mathrm{~mL})$, malar prominence $(0.4 \mathrm{~mL})$, zygoma medial $(0.6 \mathrm{~mL})$, and zygoma lateral $(0.4 \mathrm{~mL})$. In the lower third $(4.35 \mathrm{~mL})$ : mental $(1 \mathrm{~mL})$, prejowl $(1 \mathrm{~mL})$, jawline $(1.2 \mathrm{~mL})$, and ramus $(1.2 \mathrm{~mL})$. Hydryalix deep, $1.25 \mathrm{~mL}$, in the nasolabial and labiomental folds. Hydryalix lips, $1.25 \mathrm{~mL}$, in the superior and inferior lips. Total volume used: $8.75 \mathrm{~mL}$. 


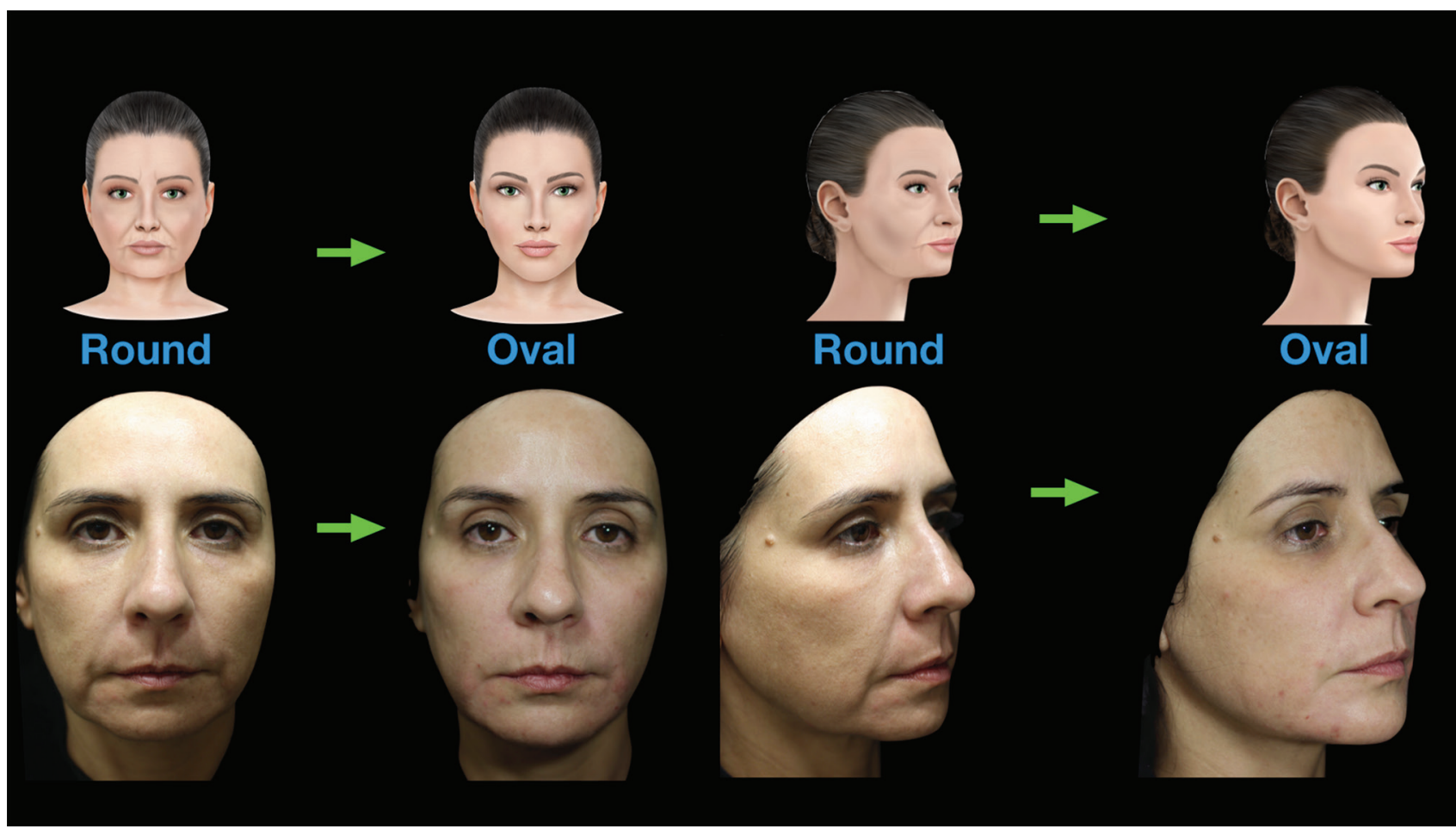

Fig. 12 Clinical example of a younger patient with a round shape face treated with Harmonyca and Hydryalix deep using the AB face technique (structure and refinement). After the treament, with improved proportions and contours of the face and a more oval face shape. Five syringes of Harmonyca, $6.25 \mathrm{~mL}$, were used. In the midface $(1.9 \mathrm{~mL})$ : malar lateral $(0.4 \mathrm{~mL})$, malar prominence $(0.6 \mathrm{~mL})$, zygoma medial $(0.6)$, and zygoma lateral $(0.2 \mathrm{~mL})$. In the lower face $(4.4 \mathrm{~mL})$ : mental $(1.4 \mathrm{~mL})$, prejowl $(1 \mathrm{~mL})$, jawline $(1 \mathrm{~mL})$, and ramus $(1 \mathrm{~mL})$. Hydryalix deep, $1.25 \mathrm{~mL}$, was used in the nasolabial and labiomental folds. Total volume used: $7.5 \mathrm{~mL}$.

- Weakness: 2- moderate or 1- fragile structure in the midface.

The beautification and rejuvenation treatments aim to improve the midface structure, improving the balance of the face ( - Figs. 13 and 14 ).

- In the middle third of the face, the filler should be injected deeply in the subcutaneous and supraperiosteal plane, and malar, malar prominence, and zygomatic areas, in upward fashion, favoring the posterior lifting of the area.

- The lower third of the face is well structured; therefore, small volume of fillers should be injected in the whole area, such as the chin, prejowls, and the mandibular line and angle.

- Injection order: middle third and then the lower third from medial to lateral.

Additionally, the use of botulinum toxin injections to reduce the masseter hypertrophy contributes to narrow the lower third, improving the balance of the angular shaped faces. ${ }^{13,14}$

The AB face structure treatment plan for the different face shapes is presented in - Fig. 15. Each face shape particular priorities in terms of areas to be treated with injectable fillers. This should be used as a general guide for the approach that must be customized for each patient, as the individuals have specific characteristics, needing different amounts of product, for example.

After treating the structure of the face, the second step is blending the areas treated, correcting remaining sulcus, the $A B$ face refinement technique. This will not be discussed in this study, although it is resumed in $\boldsymbol{- F i g . ~} \mathbf{1 6}$.

In respect to male patients, the facial shape is angular and squarer, with a stronger jawline. ${ }^{8}$ The cheeks are also less projected in the anteromedial aspect compared with female patients.

The goal of both rejuvenation and beautification treatments is to improve these characteristics and promote projection of the mandibular and mentum areas. It is important to consider the cultural particularities. Asian men prefer defined jaws but not as broad and square as the Caucasian men's preference. ${ }^{13,15}$

After the face shape is determined in the frontal view, we suggest the oblique and lateral analysis to identify the length of the face (short or long) and the mandible profile (I, II, or III). The evaluation of these two aspects provides additional help in defining the priorities of the treatment. For example, in the presence of a short face and a profile type II due to a deficiency in the mandible projection, addressing the lower third of the face to correct the proportions of the face will give a better balance, which is crucial to the best aesthetic outcomes. 


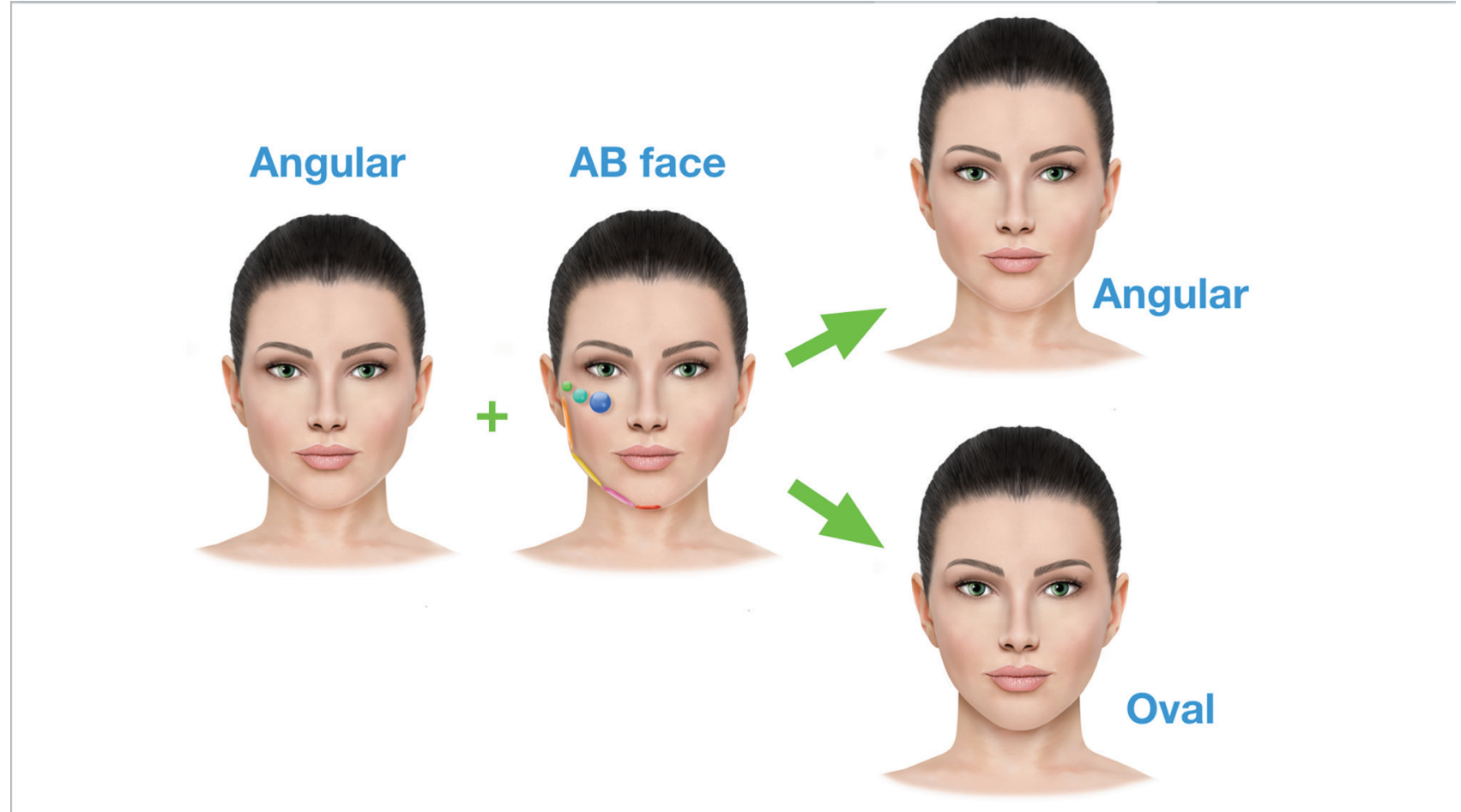

Fig. $13 \mathrm{AB}$ face technique treatment plan for the angular shape face. The technique can be used to restore volume loss and enhance beauty, keeping the angular shape or to soften into a more oval shape. In general, the volume of filler is distributed in the following proportion: $40 \%$ in the midface and $60 \%$ in the lower third of the face.

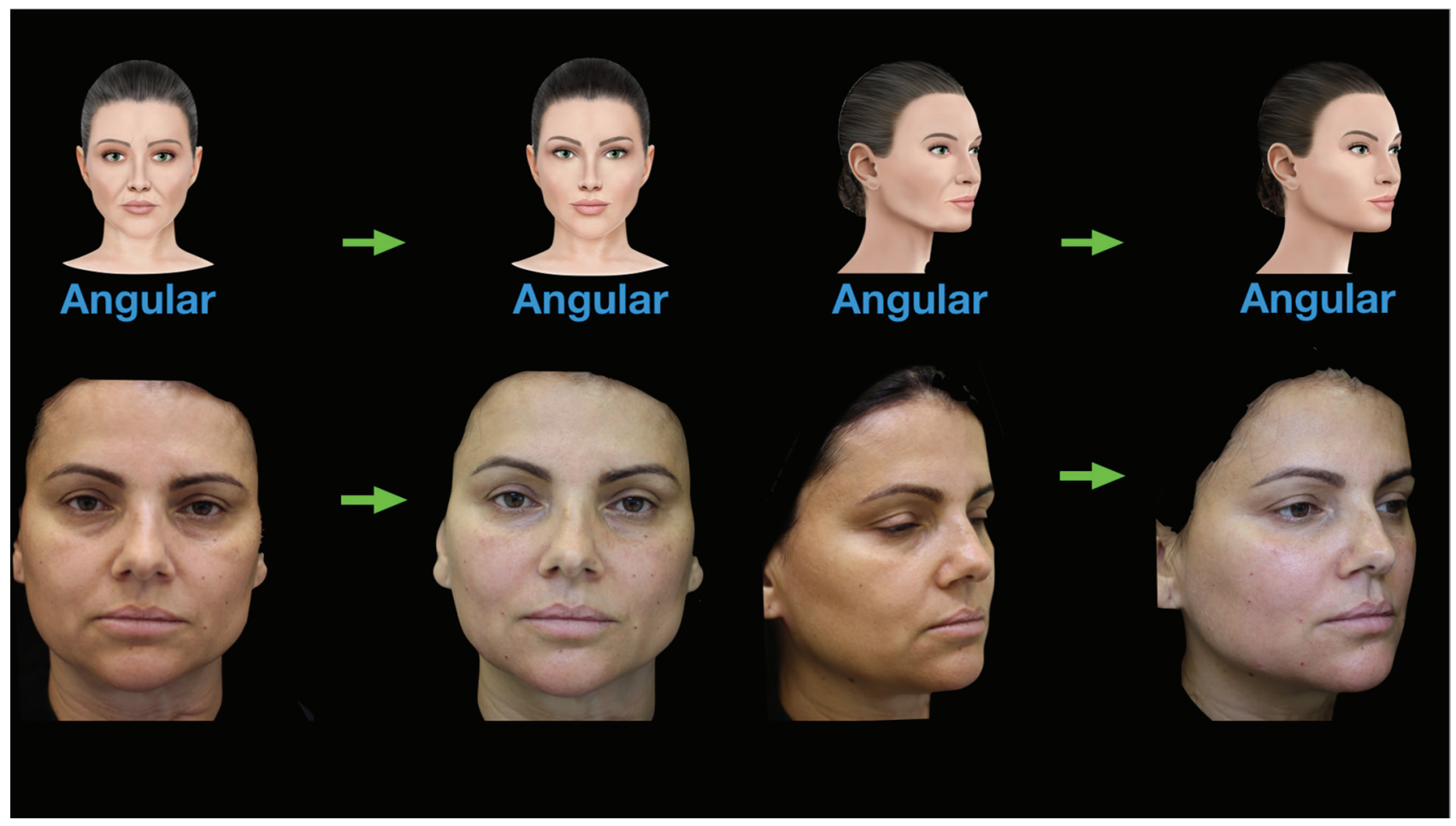

Fig. 14 Clinical example of a younger patient with an angular shape face treated with Harmonyca and Hydryalix deep and gentle, using the AB face technique (structure and refinement). A total of $3.75 \mathrm{~mL}$ of Harmonyca were used. In the midface $(1.6 \mathrm{~mL}): \mathrm{malar}$ lateral $(0.6 \mathrm{~mL})$, $\mathrm{malar}$ prominence $(0.4 \mathrm{~mL})$, zygoma medial $(0.3 \mathrm{~mL})$, and zygoma lateral $(0.3 \mathrm{~mL})$. In the lower face $(2.2 \mathrm{~mL})$ : prejowl $(0.6 \mathrm{~mL})$, jawline $(1 \mathrm{~mL})$, and ramus $(0.6 \mathrm{~mL})$. Hydryalix deep, $1.25 \mathrm{~mL}$, was used in the nasolabial and labiomental folds. Hydryalix gentle, $1.25 \mathrm{~mL}$, in the nasojugal groove and eyelid cheek junction. Total volume used: $6.25 \mathrm{~mL}$. 


\section{AB face \\ Structure}

Angular

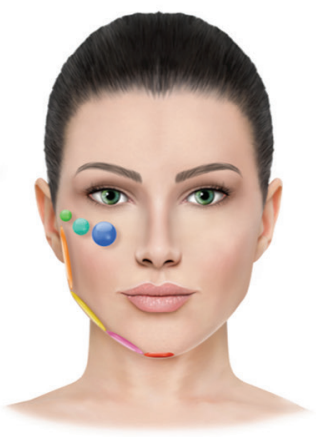

Heart

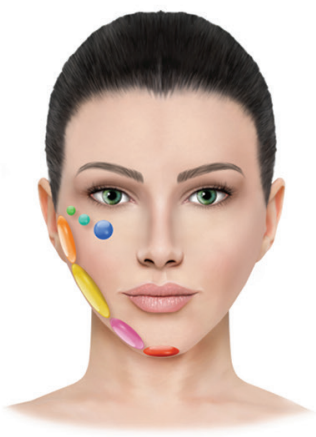

Oval

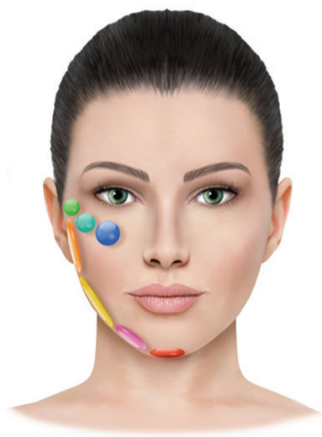

Round

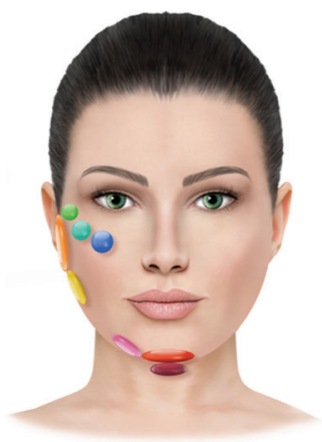

Fig. 15 The treatment areas are shown in colored spherical and elliptical figures. The size of each figure relates to the relative volume of filler needed for the treatment compared with the other areas. The larger the figure, the larger the amount of product needed for that particular region. Of note, there is a different treatment plan for each shape in terms of priorities. For example, the priorities in the heart shape are in the lower face, whereas in the angular shape, the priorities are in the midface. In the round face, the whole jawline is generally not treated.

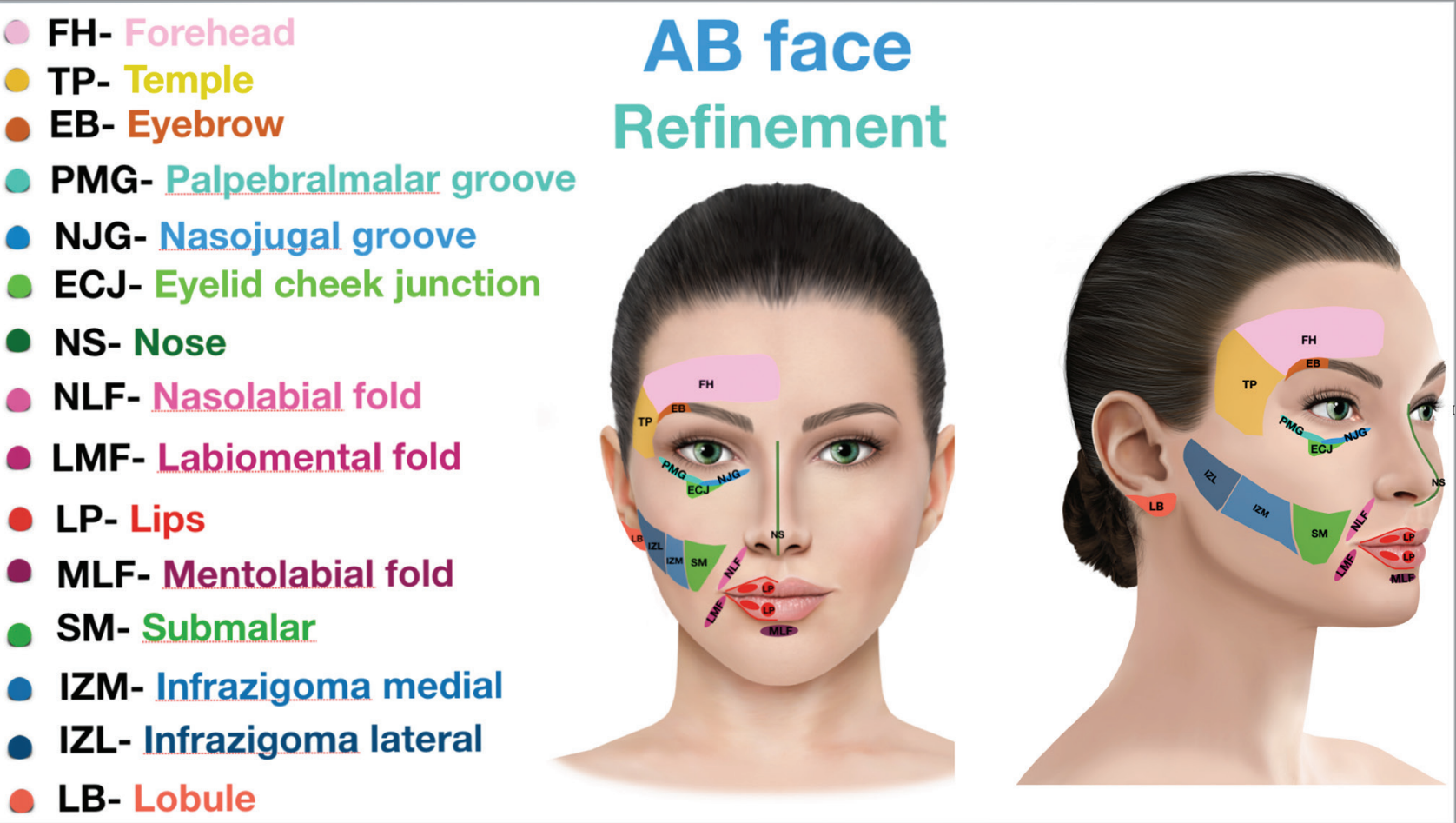

Fig. 16 The anatomical facial areas that can be treated in the refinement approach with fillers, AB face refinement. The recommendation for this technique is to use 22 - to 25 -gauge cannulas. 


\section{Facial Length}

There are three routinely described facial biotypes. In the mesofacial type, the facial width and length are balanced. The brachyfacial type is the short face, with a larger width in comparison to the length. Diversely, the dolichofacial type is the longer face. This is an academic classification, and, in general, we will find patients with intermediate features of these biotypes. Of note, if the facial length (long or short) is a remarkable feature of the patient, the strategy for treatment with dermal fillers should consider the correction of the facial proportions as a priority instead of the facial shapes strategy to achieve an aesthetically satisfactory outcome. . $^{4,16}$

\section{Mandibular Profile}

It refers to the mandibular position in relation to the skull. The neutral position is called orthognathia or class I. Class II is the retrognathia, with augmented facial convexity, which, in general, is a result of a deficient mandible volume and projection. Class III is the prognathia, with a decreased facial convexity. It can be a result of a deficiency in the maxillary area or due to an increased projection of the mandible.

This is another important aesthetic evaluation related to the proportions of the face $e^{4,17}$ and, when significant, it should guide the treatment plan instead of the facial shape strategy.

\section{Discussion}

The facial beauty cannot be explained by a mathematical formula or through an isolated aspect. Nevertheless, it can be a daily challenge to propose a treatment plan that delivers an aesthetic facial enhancement, beautification, and rejuvenation. The assessment must take into account the baseline facial features as well as the patient's subjective self-perception. ${ }^{5}$ The combination of the outer appearance and the inner spirit constitutes the natural beauty. And the aesthetic treatments can enhance the individual selfimage, which impacts the inner spirit and, in turn, improves self-esteem. ${ }^{3}$

There is a globalization of beauty in a multicultural world. The aesthetic ideals are progressively shared across the globe. ${ }^{5}$ The knowledge of the standards of beauty is of great importance to the aesthetic physician, but, above all, the sensitivity to capture the essence of each patient, which makes that person unique, is paramount.

The basic condition is to train our eyes to be able to improve our ability to understand the patient's needs. This way, we can propose a reasonable treatment plan for each patient and achieve the best outcomes.

As the shape of the face reflects its structure in terms of bone projection and subcutaneous volume, we believe that this method can help identify the priorities for treatment. For example, a round-shaped face does not need a lot of volume in the middle third of the face, whereas treating the chin area is paramount to elongate and improve the proportions. The angular face, in contrast, needs volume mainly in the malar area, and small amounts of filler can be distributed in the chin, prejowl, mandibular line, and ramus.

Recently, Farolch-Prats and Nome-Chamorro ${ }^{11}$ described a method for facial contouring using botulinum toxin and dermal fillers based on seven facial shapes, demonstrating the value of the facial morphology as a basis to deliver a whole facial approach.

Liew $^{14}$ discussed the specific morphology of the Asian faces, which are wider and shorter. It was proposed that this large width provides greater structural support against tissue sagging, influencing their aging process. However, Asian women consider an oval-shaped face desirable, and for this reason, treatments with facial injectables were discussed to optimize the facial proportions into an oval facial shape.

Chao et $\mathrm{al}^{13}$ in a consensus for the treatment of Asian patients with fillers, toxins, and ultrasound devices also discussed the preference for an oval facial shape and proposed combined treatment strategies for beautification modifying the facial shapes. ${ }^{13}$

We believe that some of the proposed facial shapes show similar characteristics; therefore, using a classification with a smaller number of facial shapes is easier to understand and more practical in the definition of the aesthetic treatment plan. For that reason, we have been using four face shape models: oval, heart, round, and angular.

The $A B$ face technique is a method to plan and deliver the aesthetic approach with fillers, taking into consideration the facial shapes. The treatments with this technique are delivered with cannulas, in retrograde injection, to distribute the product.

After addressing the structure of the face with the first step, the $A B$ face structure, sulcus and lines may be softened with the second step, the $A B$ face refinement.

Of note, it is known that other methods of treatment besides fillers are important to improve the facial contours, such as botulinum toxin, which was not the scope of this study but can be combined with the $\mathrm{AB}$ face technique.

Having a method to perform the facial assessment is of great importance, and, in fact, there are different good ways to do so. Our intention is to share our view of beauty to describe a strategy of treatment with fillers based on our personal experience.

\section{Conclusion}

The face shape reflects the facial structure, the volume and projection of bone, subcutaneous tissue, and skin. It also relates to gender, attractiveness, and age. For these reasons, we propose the $A B$ face technique, which the first step is $A B$ 
face structure, which means planning the aesthetic treatment with injectable fillers based on the four face shapes.

We find that this approach can provide beautification, rejuvenation, and, moreover, enhancement of the facial structure, which will benefit facial volume and contours through aging.

After approaching the structure of the face, additional treatment with fillers is used to smooth the areas to correct any sulcus or shadows left, which we call the refinement treatment, $A B$ refinement. This is performed using softer hyaluronic acid gels appropriate to a more superficial placement in the subcutaneous plane.

Finally, we understand that to achieve optimal patient outcomes, it is crucial to understand the facial anatomy and how to prevent, identify, and manage the possible adverse events. Also, a combination of different methods of treatment is required, but this was not the objective of this study.

We hope that this study might be helpful in giving an insight into and a practical view of how to plan a treatment with injectable fillers in an effective manner.

Before and after, with improved proportions of the face, keeping the angular shape.

\section{Conflict of Interest}

None.

\section{References}

1 Rhee SC, Lee SH. Attractive composite faces of different races. Aesthetic Plast Surg 2010;34(6):800-801

2 Goodman GJ. The oval female facial shape- a study in beauty. Dermatol Surg 2015;41(12):1375-1383

3 Sands NB, Adamson PA. Global facial beauty: approaching a unified aesthetic ideal. Facial Plast Surg 2014;30(2):93-100

4 Braz A, Sakuma T, Atlas de Anatomia e Preenchimento Global da Face. $1^{\text {a }}$ edição. Guanabara Koogan. Rio de Janeiro, Brazil; 2019
5 Shamban A. The signature featureTM: a new concept in beauty. J Cosmet Dermatol 2019;18(3):692-699

6 Langlois JH, Reggiman LA, Musselman L. What is average and what is not average about attractive faces? Psicol Sci 1994;5:214-220

7 Lam SM, Glasgold R, Glasgold M. Analysis of facial aesthetics as applied to injectables. Plast Reconstr Surg 2015;136(5, Suppl):11S-21S

8 de Maio M. Ethnic and gender considerations in the use of facial injectables: male patients. Plast Reconstr Surg 2015;136(5(Suppl):40S-43S

9 Toledo Avelar LE, Cardoso MA, Santos Bordoni L, de Miranda Avelar L, de Miranda Avelar JV. Aging and sexual differences of the human skull.Plast ReconstrSurg Glob Open 2017; 5(4):e1297

10 Villanueva Sagrado M. Forma y fenótipo facial. Estudios de Antropologia Biológica 2003;11:599-616

11 Farolch-Prats L, Nome-Chamorro C. Facial countouring by using dermal fillers and botulinum toxin A: a practical approach. Aesthetic Plast Surg 2019;43(3):793-802

12 Heydenrych I, Kapoor KM, De Boulle K, et al. A 10-point plan for avoiding hyaluronic acid dermal filler-related complications during facial aesthetic procedures and algorithms for management. Clin Cosmet Investig Dermatol 2018;11:603-611

13 Chao YY, Chhabra C, Corduff N, et al. Pan-Asian consensus. Key recommendations for adapting the World Congress of Dermatology Consensus on combination treatment with injectable fillers, toxins and ultrasound devices in Asian patients. J Clin Aesthet Dermatol 2017;10(8):16-27

14 Liew S. Ethnic and gender considerations in the use of facial injectables: Asian patients. Plast Reconstr Surg 2015;136(5, Suppl):22S-27S

15 Samizadeh $\mathrm{S}, \mathrm{Wu} \mathrm{W}$. Ideals of facial beauty amongst the Chinese population: results from a large national survey. Aesthetic Plast Surg 2018;42(6):1540-1550

16 Jefferson Y. Skeletal types: key to unraveling the mystery of facial beauty and its biologic significance. J Gen Orthod 1996;7(2):7-25

17 Reis SAB, Abrão J, Capelozza Filho L, Claro CAA. Análise facial subjetiva. Rev Dent Press Ortodon Ortop Facial 2006;11(5):159-172 